\title{
Research on Applications of PBL Teaching Model in Higher Mathematics Teaching in Application-oriented Colleges
}

\author{
Wenyao Xiong ${ }^{1, a}$, Haijian Cui ${ }^{1, b}$ \\ ${ }^{1}$ Nanchang Institute of Science \& Technology, Nanchang, 330108, China \\ a531322676@qq.com, b120290446@qq.com
}

Keywords: PBL teaching model; application-oriented colleges

\begin{abstract}
The teaching of higher mathematics in application-oriented colleges has always been the difficulty of higher education. This paper analyzes the concept and main advantages of the PBL teaching model and applies it to the higher mathematics teaching in application-oriented colleges. Taking the teaching of infinite series as a case, this paper discusses the application process of PBL teaching model in higher mathematics teaching in applied undergraduate colleges, including problem proposal, problem analysis and solutions. The practice shows that the final exam scores of the PBL experimental classes are obviously higher than those of the control class.
\end{abstract}

\section{Introduction}

The transformation of teaching mode and the selection of teaching content are the key to the reform of teaching. [1] For a long time, higher mathematics is mainly based on the traditional classroom teaching mode. Although the teaching reform means emerge in an endless stream in recent years, the effectiveness of these methods is not obvious. This is mainly because teachers in traditional classroom teaching as the main body of the teaching process, often focus too much on the logic and the system of strict mathematical derivation and problem solving, and exercise the proof of the theorem, the formula, the mathematical knowledge is presented in what kind of practical application background, and how to use these math knowledges to solve practical problems but speak very little. The direct result of teacher-oriented teaching is neglecting the dominant position of students, neglecting the cultivation of students' innovative spirit and creativity, and students only passively accept knowledge as an object. How to explore a new teaching mode to meet the needs of the development and reform of higher mathematics teaching and improve the quality of higher mathematics teaching is very important and urgent. In the teaching of advanced mathematics, most teachers have explored and applied the teaching mode and teaching method, and tried to explore teaching methods such as inquiry, seminar, analogy, PBL and so on. After several years of teaching practice, we all agree that PBL teaching method plays an important role in developing students' self-learning ability, analyzing and solving problems.

\section{Concept and Main Advantages of PBL Teaching Model}

\subsection{Concept of PBL Teaching Model}

PBL (Problem-Based Learning) teaching method, also known as problem-based approach, problem-based learning and problem driven teaching, is a teaching method implemented by Howard Barros, a professor of Neurology in 1969. The PBL teaching method is very different from the traditional "transfer - Acceptance" teaching method. "Transfer - accept" teaching method is a teacher, the students only pay attention to the teacher as a supplement; instilling knowledge to students, while ignoring the cultivation of students' ability; in the classroom, teachers teach what students passively accept what students, too lazy to think. PBL teaching method is problem centered, with students as the main body and the teachers as the leading teachers; no longer simply pass and explain knowledge, and pay more attention to the cultivation of students' abilities; teachers in the classroom, through the creation of problem situations, based on the teaching problems, let students always found and study 
of the situation to solve the problem, by allowing students to learn the knowledge behind the problem, thus cultivating students' creative thinking ability and learning ability goals. If the teacher can let the students solve the railway in turn why railway to Banet rail height of this practical problem, and finally grasp the "curvature" concept; let the students solve the optimal route problem, grasp the concept of "extreme conditions"; let the students solve the problem if the apple branch only read textbooks, students do not to realize the use of higher mathematics, but noted that the PBL teaching method is by letting students solve the practical problems in life or in engineering, related knowledge to learn higher mathematics problems [2].

\subsection{Main Advantages of PBL Teaching Model}

PBL teaching mode can stimulate students' enthusiasm and initiative in learning mathematics, problem is the inspiration for thinking, and the starting point of innovation [3]. Once people find problems, they will generate the psychology of inquiry. The organization of higher mathematics teaching application of PBL teaching method in teaching, teachers and students as the creation of the problem situation to solve the problem of guidance, will focus on knowledge questions constantly, so it requires students to constantly seek ways to solve the problem, and then we can make the students potential curiosity is active, they will active thinking, thus unconsciously involved in teaching activities. As the main body of learning, young learners are very fond of enjoying this challenging and stimulating process. They like to enjoy the joy of success in such a process, which is not for teachers' preaching. In the teaching of higher mathematics, some students often ask questions about how to learn higher mathematics. This can solve the problem that the content of higher mathematics textbook is not closely related to the reality of life and engineering application, and students' interest in learning is not high, and learning is useless. It can also cultivate students' ability to solve problems. PBL teaching mode is to put forward the problem, analysis problem, solve the problem in 3 aspects throughout the teaching process, to cultivate students' comprehensive application of knowledge to solve the question ability, innovation consciousness and self-learning ability as the key point, the formation of "teachers guide, students explore learning" mode. In this mode the key teachers is to play a guiding role, while the students become the subject of teaching, which can make the students feel the process of using knowledge to solve problems, truly reflect the essence of the PBL teaching mode of taking students as the main body, shape independent of students, cultivating students' innovative ability and understanding ability to acquire new knowledge, effective use knowledge to solve new problems, have a solid theoretical foundation for the students and provide a guarantee with strong ability of engineering practice. The core of the PBL teaching model is the problem. These problems are mainly based on cases, and cases become the key to the construction of PBL teaching model. Through case teaching, with the background of practical application of theoretical knowledge, it reflects the application of Higher Mathematics in the major courses and practical life of students. This is an effective way to improve the students' interest in learning and the effect of teachers' teaching [4].

\section{Application Flow of PBL Teaching Model in Higher Mathematics Teaching in Application-oriented Colleges}

The most prominent requirement in the PBL teaching model is that teachers should create a suitable problem situation. The practice has proved that the independent discovery of the problem and the independent solution of the problem can improve the students' desire for knowledge and fully arouse the students' desire for exploration and subjective initiative. We take the PBL teaching of infinite series as an example to show the application process of BL teaching mode in Higher Mathematics Teaching in applied undergraduate colleges.

\subsection{Problem Proposal}

The creation of the actual situation, the "problem for the lead, teachers are required to address the teaching content and concept and application of different types of students and the level of knowledge to create wizard corresponding problem scenarios; can also put forward their problems in students. 
Guide them to different types of problems. Using the induction, discussions and exchange analysis, interpretation, and other ways to explore the counterexample, grasp the knowledge by solving problems, to achieve the goal of teaching. It is an important means to arouse the students' positive thinking and to learn to think independently. Set up a series of problems in the process of teaching, knowledge will be perfectly Taiwan in the problem, so that the students were unable to restrain the emotions the problem of the situation of people thinking. Giving play to the subjective role of students' learning, when introducing the main content of this chapter, we can give an example of someone who wants to deposit a sum of money in the bank, and the way of deposit is calculated according to the annual interest rate. The annual interest rate of the bank is that the depositors want to take out the yuan at the end of the year. Can the aspirations of the depositors be realized? The ancient philosopher said: a foot of the whip, the half day, there will be no end. Now add up a part of the length of every cut. The result is $\frac{1}{2}+\frac{1}{2^{2}}+\frac{1}{2^{3}}+\cdots+\frac{1}{2^{n}}+\cdots$. The addition of infinite numbers is a finite number. The two major problems to be explained in this chapter are series. The first is the problem of series multiplication. The two is the existence and existence of infinite numbers, if and how to solve them. With these problems, students can feel the practicality of the series and guide the students to begin the study in this chapter.

\subsection{Problem Analysis}

Two questions are raised by the teacher. First, whether the sum of infinite numbers is added or not; second, the sum of infinity numbers and whether it is a definite number. Then the students discuss the two problems, when the students fully free combination, make the different characteristics of the students as a group, as much as possible for students to cooperate with different opportunities for students to enhance project freshness, keep students' interest in learning, usually a group of five people. In guiding the implementation of project teaching, teachers give full play to students' autonomous learning, and discuss a major point of view of the integration and formation of the group. When there is a disagreement within the group and no agreement can be reached, the teacher should provide the right way for the students to return to the correct approach to the analysis of the problem. In recent years, in the practice of teaching method reform, the author creates teaching situations through case teaching, introducing content of mathematics history and so on, to stimulate students' interest in learning advanced mathematics and their inner learning motivation. In the class to count the, numbers and contact problems of high school students have been circulating decimal radian learned. The series is the synthesis of the two parts of the sum of the series and the limit of the series, so the teacher should clarify the relationship between them in the teaching. In explaining the concept of series, the emphasis should be on the relation and difference between the series and the series. The reason is that the participants of the series are mainly the items of the series. On the one hand, the general term of series is the general term of series. On the other hand, series is the limit of number sequence and sequence of series. Where the sum of infinite numbers is the essence of series, we will help students better understand the concept of series convergence and divergence. The series is the sum of the infinite countable number. Its convergence is determined by the convergence and divergence of its part and the series. When the series converges, its sum is a finite number; when the series is diverged, it is only an expression, without any meaning. The summation of series is different from that of the sum of the finite number. For example, the addition law does not necessarily apply to the series.

\subsection{Problem Solution}

Judging the convergence and divergence of a series is an important part of series. Besides the use of definition to decide convergence and divergence, there are many very useful judging methods, which is the main content of subsequent chapters. When using these decision methods, we need to use harmonic series and geometric progression related conclusions, so we need students to master the knowledge of these two kinds of series. These two kinds of series, convergence and divergence and judge in the back chapters will be used repeatedly, especially the positive series comparison criterion and limit criterion in use, with the two series as the benchmark series comparison so that teachers in 
the teaching, students should be repeated to emphasize, to deepen our impression. Because we don't know the convergence and divergence of series in advance, we don't know whether the series itself is enlarged or narrowed, so there is no sense of direction, so the comparison method is relatively flexible, which is a difficult way to grasp. The characteristic of the above theorem is how to select a suitable known convergent or divergent series of datum series is the key to solve the problem. The advantage of the ratio method of convergence does not need to find another comparison base series. Compared to the "comparative convergence law", it is more useful and more advantageous. When the teacher teaches, it should be introduced as a key point. Therefore, when judging the convergence of series, we first consider the ratio checking method. The drawback is that when the ratio of the entries to the limit is 1 , the method fails. If we use the ratio method, we will fail. Therefore, if students want to use the ratio discriminant method, we should first understand the characteristics of the ratio discrimination method. We need to judge that the limit of the item ratio will be 1 . when the series is in ten cases. When the method fails, consider the comparison method and find a reference series. In addition, we should pay more attention to the scope of application of the limit form of the method of comparative convergence.

\section{Application Results of PBL Teaching Model in Higher Mathematics Teaching in Application-oriented Colleges}

We selected two parallel classes in different departments of grade 2017. One class is selected as the experimental group, and the other class is selected as the control group. The implementation of case teaching method under the PBL model in the experimental class, compared research group knot exams average scores of the experimental group and the control are shown in Table 1. It was found that the students' scores in the experimental group were generally higher than those of the control group.

Table 1. Average score comparison of experimental group and control group

\begin{tabular}{|c|c|c|c|c|}
\hline Major & $\begin{array}{c}\text { Logistics } \\
\text { management }\end{array}$ & $\begin{array}{c}\text { Financial } \\
\text { management }\end{array}$ & $\begin{array}{c}\text { Civil } \\
\text { engineering }\end{array}$ & $\begin{array}{c}\text { Electrical } \\
\text { engineering }\end{array}$ \\
\hline $\begin{array}{c}\text { Average score of } \\
\text { experimental group }\end{array}$ & 87 & 92 & 93 & 85 \\
\hline $\begin{array}{c}\text { Average score of } \\
\text { control group }\end{array}$ & 76 & 81 & 77 & 80 \\
\hline
\end{tabular}

\section{Conclusion}

PBL teaching mode is a new teaching idea and teaching method. Based on PBL mode, case teaching method of advanced mathematics can improve students' learning enthusiasm and initiative, improve their logical thinking ability and comprehensive analysis ability, and harmonize the relationship between teachers and students. The rich practical cases provide a broad resource for the problems in the PBL teaching model, and provide a guarantee for the effective implementation of the PBL.

\section{Acknowledgment}

The project name is "Research on Applications of PBL Teaching Model in Higher Mathematics teaching in Application-Oriented Colleges” (Grant No. NGJG-16-04).

\section{References}

[1] Ren Qiuping, Ren Shijun, Zhou Guangming. Research on case teaching method of higher mathematics course based on PBL mode [J]. Journal of Science of Teachers' College and University, 2017, 37(4): 73-75. 
[2] Hu Jingbo. An Exploration on the teaching mode of "PBL+modular" in Advanced Mathematics [J]. The Journal of Shandong Agriculture and Engineering University, 2017, 34(6): 100-101+117.

[3] Zhang Bo, Leng Ping. Reform and Study on Teaching Methods of Higher Mathematics [J]. Journal of Huaibei Normal University (Natural Science Edition), 2016, 37(1): 78-82.

[4] Li Xiaoxia. The Discussion of Advanced Mathematics Teaching in Applied Colleges [J]. Journal of Yuncheng University, 2012, 30(2): 64-66. 